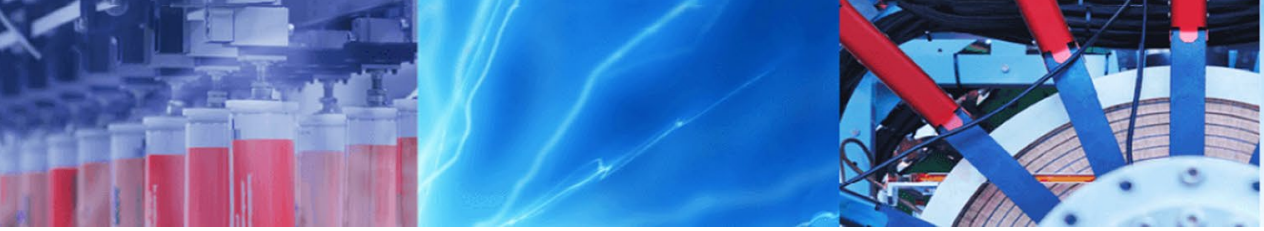

Research Article

\title{
An analysis of structural aesthetics in architecture case study: Taj-OI-Molk Dome, Jāmeh Mosque of Isfahan, Iran
}

\author{
Sara Sadeqi ${ }^{1} \cdot$ Ahmad Ekhlassi $^{2}$ D $\cdot$ Saeid Norouzian-Maleki ${ }^{3}$
}

(c) Springer Nature Switzerland AG 2019

\begin{abstract}
The role of structure has been always considered essential in understanding the architecture. In the historical buildings of Iran, the function of structural elements follows the general form of the building. In this study, the modern structural analysis of historical building aimed at discovering the deep knowledge of experienced and skilled constructors in their works, developing the modern structural theories, and establishing modern solutions for strengthening of structural elements. Taj-Ol-Molk Dome was used as the case study that it is entitled to "the most beautiful dome". In this study, the qualitative and interpretive method was used to explore the role of aesthetics in Iranian domes. In the structural analysis based on structural simulation, the total displacement was less than 0.0002 at the maximum mode. In addition, the Von-Mises stress at the joint bearing surfaces was $2.3 \times 10^{6}-3.5 \times 10^{6}$ which was less than the yield stress of the materials. Based on Mohr-Coulomb theory, the entire structure is below the standard risk level. A variety of brickwork styles were used based on mathematical calculations to reduce applied forces to the building. The form of Taj-Ol-Molk Dome is completely in harmony with the catenary curve form. The structural patterns lead to the bearing stress as completely compressive and without tensile and bending stress. Based on the findings, the golden ratio in the façade of building coordinated the cross section and dome-span. Finally, the structural features of the dome and the principles of structural aesthetic vision of the building are explained.
\end{abstract}

Keywords Structural aesthetics · Iranian architecture · Taj-OI-Molk Dome · Structural principles

\section{Introduction}

During the Roman Empire, Vitruvius considered Firmitas (Strength), Utilitas (Functionality), and Venustas (Beauty) as three main elements of architecture. These translated into sustainability, product, and delight in the seventeenth century. Delight is a word to express the effect of building on the aesthetic sense of the people [1]. Indeed, aesthetics is the harmony that coordinates the pleasures in a certain way and creates beautiful thought.

The term "aesthetics" is a Greek word meaning "perception". Mankind has paid attention to the spiritual needs and aesthetics sense deals with the architecture. For instance, the first residential settlements have shown the notion of beauty. Besides, based on the analysis of architectural masterpieces which are placed among the most valuable works, the existence of the aesthetics is observed [2]. Actually aesthetics and elegance make timeless the architecture. The beauty of architecture focuses on the structural behavior and the elements of the facade as a united element must have aesthetics appeals and engineering considerations simultaneously [3]. The main purpose of architectural design is creation of forms that provide both functional requirements of the building and aesthetics aspects. Also, the main goal of structural design is creation of structural forms that both provide the functional

$\triangle$ Ahmad Ekhlassi, ekhlassi@iust.ac.ir|' School of Architecture and Environmental Design, Iran University of Science and Technology, Tehran, Iran. ${ }^{2}$ School of Architecture and Environmental Design, Iran University of Science and Technology, Tehran, Iran. ${ }^{3}$ Faculty of Architecture and Urban Planning, Shahid Beheshti University, Tehran, Iran.

SN Applied Sciences (2019) 1:570 | https://doi.org/10.1007/s42452-019-0558-5

Received: 20 January 2019 / Accepted: 3 May 2019 / Published online: 15 May 2019 
needs and withstand the applied loads more efficiently and economically. In terms of close collaboration between architects and structural engineers, the main task of engineers is to create of works which provide functional and economic needs as they have desirable appearance and architectural aesthetics features simultaneously [4].

The structure plays a major role to create a form as one of the main components of the design. Therefore, structural form is one of the structural components. Structural form is the creation of the beauty through the proportional dimension to facilitate the flow forces to a structural system that is important. Thus, designers should also consider the direction of the force to achieve a perfect composition in the form [5]. When a form is designed without any structural considerations, two important issues can occur. Firstly, because the form is non-dynamic, we have to deal with the bending moment. Secondly, the amount of internal forces will probably be high in comparison with applied load. As a result, materials and structures are used inefficiently. In addition, the dimension of elements is needed to provide adequate resistance will increase that lead to unstable and formless structures [1]. According to definitions mentioned above, the aesthetics of structure will create a form based on structural principles, optimal mass and transition of the forces.

According to the scholars discussed, the subject has many definitions and common aspects such as the ratios between the structure components and the total unit, the ratio between the structure and its surroundings, structure validity, and the perception of structural forms based on natural structures [6].

According to Salvadori and Heller [7], aesthetics of structures refers to the correctness of the structure. In addition, pure structural messages originate in the fundamental understanding of the structural behaviour that stems from the physical experience and perception of structural forms in nature. These perceptions are part of a set of values that lead to aesthetic development.

Faber [8] believed that structural factors for achieving the aesthetic satisfaction include a specific and considerable attribute, harmony, and composition. Kular [9] defined the structural aesthetics by the criteria of (a) discipline (architectural organizer), (b) ratios, rhythm, symmetry, and asymmetry, (c) geometric and completed form, (d) unique feature, (e) form as the expression of static behavior, (f) ratio between structure and environment.

According to Le Corbusier [10], aesthetics includes the principles such as materials efficiency, forces motion and structure. Margolius [11] claimed that the architectural structures can participate in creating a particular beautiful image from building if they are designed with enough sensitivity and skill. Structural aesthetics cannot exist without the structural correctness. According to
Schumacher [12], the modern aesthetics is derived from the twisted spirit of nature, oscillation of molecules, and geometry of genes. Aesthetics is the regular complexity and integrated fluidity. Finally, Andrew [13] emphasized that factors such as modulation, depth and texture, and design of details can become a tool for developing the sense of aesthetics.

\section{Research questions}

The present research aims to find answers to the following questions:

- What is the necessity for identifying the principles of structural aesthetics in architecture?

- What is the role of aesthetics in Iranian domes and how is it manifested?

- How is the realization of these principles in the contemporary architecture?

\section{The aesthetics of dome in Iranian architecture}

In Iranian historical buildings, considering the structural properties such as resistance, hardness, and stability as the main criteria of design is meaningless. Measuring stress is in the second rank of importance although a traditional architect is completely aware of the forces, stresses, and structural damages. The function of structural elements follows the general form of the building [14].

A historical building is unlikely to have an inappropriate design and construction regulations based on the modern structural engineering standards. The modern structural analysis of historical buildings is a powerful tool for exploring the deep knowledge of traditional constructors in their works and developing the modern structural theories, and establishing modern design techniques in the contemporary architecture to solve the structural/aesthetic problem. As a main principle in the traditional building construction, the function and sustainability of buildings follow the geometry [14].

Taj-Ol-Molk Dome is located behind the northern porch of the Jameh Mosque of Isfahan, known as Sofeh Darvish, ${ }^{1}$ at the extreme north of the mosque building, which was used as the case study. It is entitled to "the most beautiful dome" from the perspective of some researchers such as

\footnotetext{
1 Sofeh [soffe]: Roof-covered, platform without a roof and with a surface higher than the yard and is typically placed in front of the closed spaces [23].
} 
Fig. 1 The position of Taj-OlMolk Dome in Jameh Mosque of Isfahan

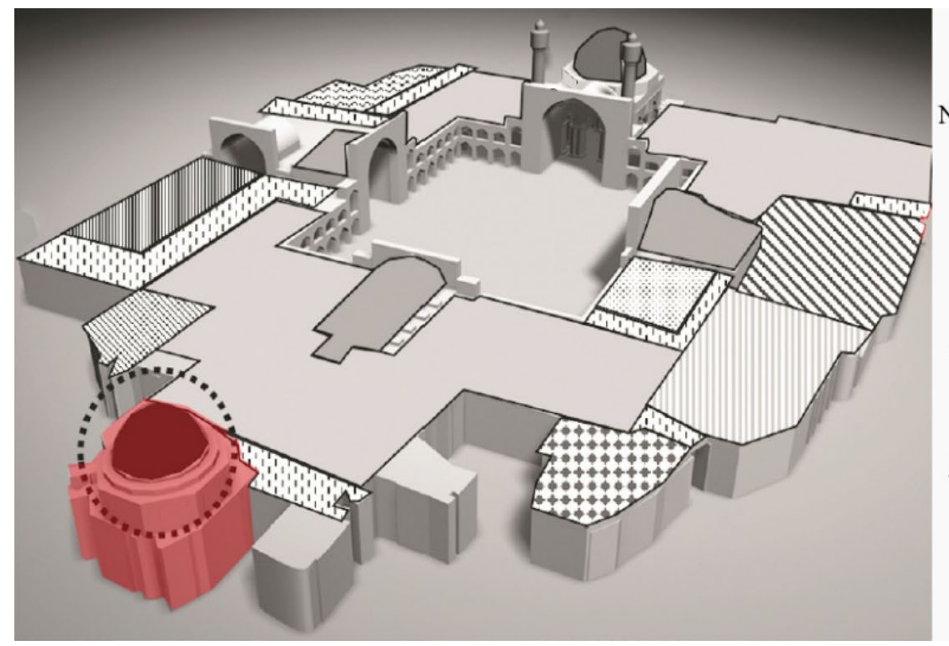

Nezam Ol-Molk dome

Taj Ol-Molk dome Iwan seraglio winter seraglio lavatory $\mathbb{m}$ Dervish prayer room linking paths लास्माप

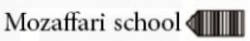

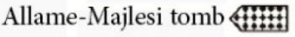
library sisg Oljaito hall yard
Pope, Schroeder and Grabar [15]. The dome was constructed upon the order of Turkan Khatun in 1088 A.D. [16]. This building was designed as square shape with internal dimensions from 9.80 to 10 metres, external dimensions of 14 metres, and approximate height of $20.60 \mathrm{~m}$. The square plan of the dome turns into octagon, hexadecagon, and finally into a circle through vaulting arches. The dome was used to cover a span of $9.50 \mathrm{~m}$. It was built on a base with appropriate thickness of $3 \mathrm{~m}$. The dome is a single shell and its height from the top to the ground is about $18.50 \mathrm{~m}$ and from the arch dome to the top about $7 \mathrm{~m}$ having a relatively large deflection [17]. The shell thickness varies from $0.36 \mathrm{~m}$ at the top to $0.66 \mathrm{~m}$ at the base. The vertical section form of the dome is a combination of two crossover arches [18] (Fig. 1).

Schroeder considered the dome to be of strange beauty and perfection based on mathematics principles. The aspect ratio of the ground plan stems from the magic number of three. The internal curvature of the dome is such a pentagon that is created between the equilaterals and fell into the arms of acute angles towards the inside [19].

The internal height of the dome is more than twice the length of its base. In addition, the line forming the beginning of the transitional zone divides the total height into two parts whose ratio is equal to the golden ratio. Also, the ratio of the main vault heights in the upper floor to the lower floor is based on the golden proportion [20].

Oleg Grabar (1990) asserted that the ratio of the north dome is exactly equal to Khayyam's triangle. These measurements were based on aerial photographs taken by the Survey Organization [20].

Hejazi and Mehdizadeh Saradj achieved the similar results through the precise analysis. They used the finite element method and NISA II Finite Element Analysis Software to analyze the structure of the building. Based on seismic load analysis, the followings are mentioned:
1. Meridian force $\mathrm{N} \varnothing$ is compressive everywhere and increases towards the base.

2. Orbital force $\mathrm{Ne}$ from the base to $2 \mathrm{~m}$ below the top where the pressure is insignificant. The maximum value of the force is achieved at two metres above the base.

3. Bending moment Mø becomes too small along the height of the dome.

4. Bending moment $\mathrm{Me}$ in the dome can be ignored.

5. Meridian stress $\sigma \theta$ is always compressive and its maximum value is $7 \%$ of the allowable compressive stress at the base [18].

In Taj-Ol-Molk Dome, the change in angle and thickness was due to increasing strength at critical stress point $51^{\circ} 50^{\prime}$. According to the mathematical relations that solving the balance equation for spherical dome under the weight load, Hejazi and Mehdizadeh Saradj [18] indicated that the orbital force symbol $\mathrm{Ne}$ changes from negative (compressive) to positive (tensile) $(\mathrm{Ne}=0)$. The masonry materials have a weak resistance to tensile effects. Hence the crack occurs at this point (Figs. 2, 3).

\section{Methods}

In this study, the qualitative and quantitative methods were mixed within the data analysis and data interpretation stages. The mixed-method approach was used with the aim of providing a more complete picture of the concept of "principles of structural aesthetics in architecture" [21].

In order to analyze the findings obtained from the scholars, the content analysis techniques were used to interpret the concepts in more meaningful manner. The following process was used for thematic analysis: 


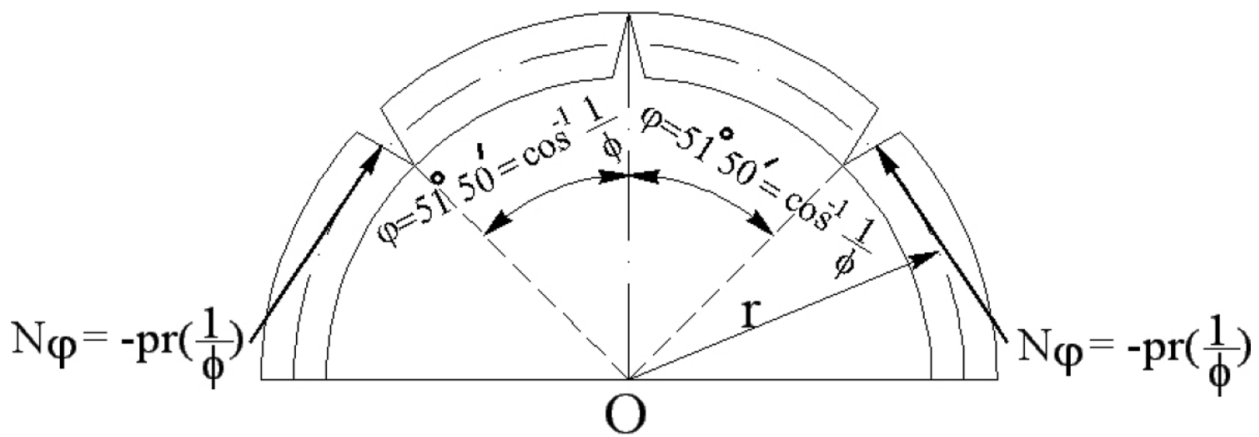

Fig. 2 The pattern of crack based on the Golden ratio in a spherical arch under the weight load. The analytical research including the above-mentioned factors related to Taj-Ol-Molk Dome indicated

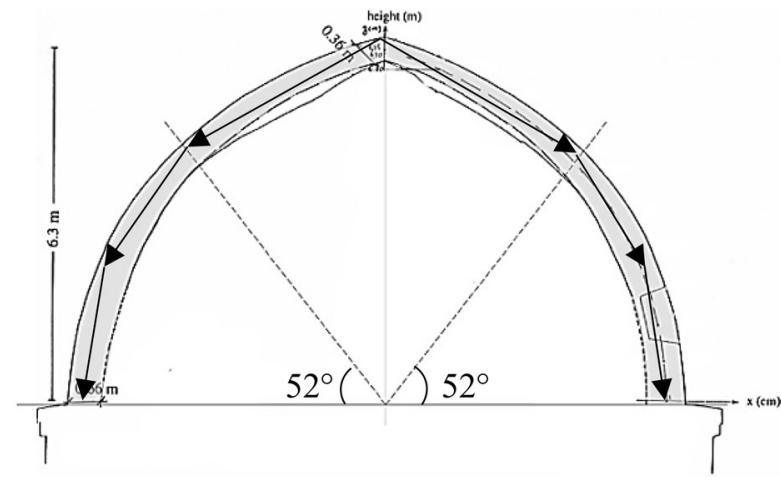

Fig. 3 The change of the angle and thickness due to increasing strength at the critical stress point in Taj-Ol-Molk Dome

- Determining the research topic and objectives, to identify appropriate methodologies and to develop research

- Encountering the texts and documenting their features

- Dividing the texts into smaller units of meanings or unit of analysis

- Quantifying the units of analysis

- Using the descriptive-inferential test to explore the case study of Iranian architecture (Taj-Ol-Molk Dome)

\section{Theoretical framework}

According to the well-known scholars, as mentioned in the research literature, the findings obtained from the content analysis revealed the principles of structural aesthetics. The criteria divided into two categories: the work-related factors and the external factors (environment and audience). The factors related to the work include mystical factor, structural factors, formal factor, and natural factor. Formal factor includes the skeleton and content. The skeleton part is divided into physical and semantic sub-groups [6] (Figs. 4, 5).

SN Applied Sciences that geometry and topology of the building had a direct relationship with the stability. The Golden ratio (geometric ratios) is superior to stability (mechanics) [14]
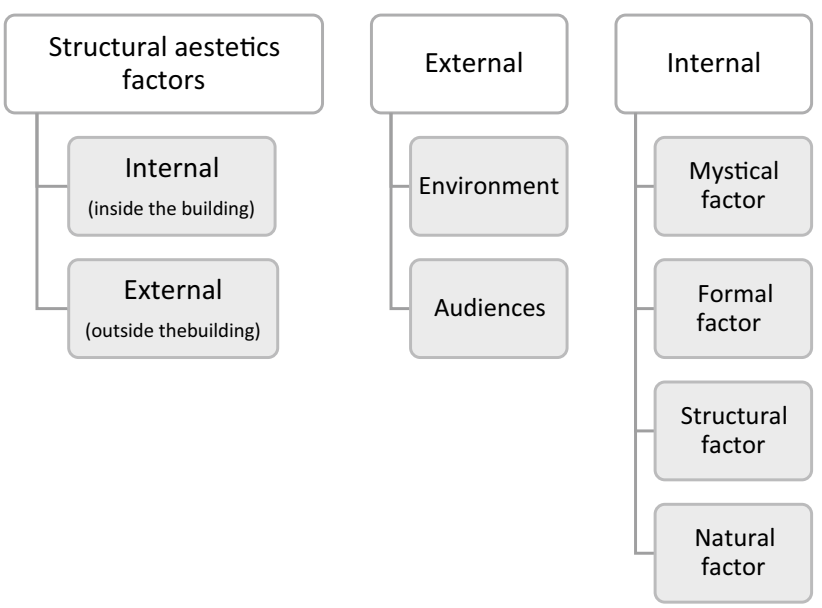

Fig. 4 The relationships between internal and external criteria of structural aesthetics

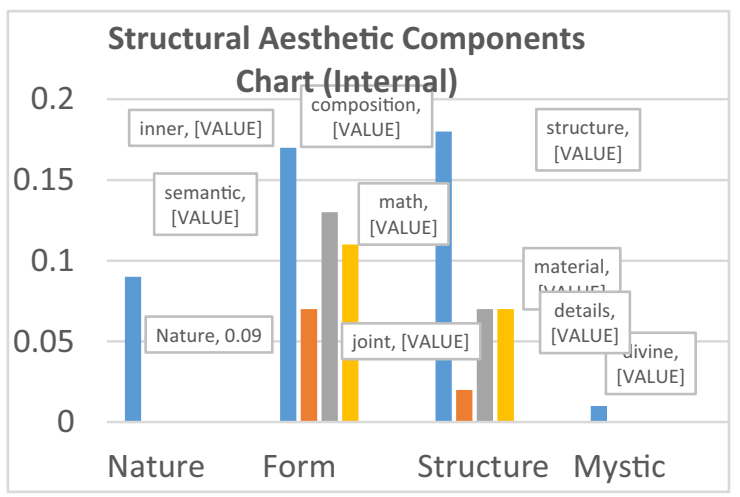

Fig. 5 Units of Analysis based on the scholar's theories

In order to analyze the role of structural aesthetics based on theoretical framework, Taj-Ol-Molk Dome was separately analyzed by each criterion to explore the realization of all factors. 
Table 1 Analysis of maximum and minimum displacement

\begin{tabular}{|c|c|c|}
\hline & Amount (m) & Location \\
\hline \multicolumn{3}{|c|}{ Displacement summary } \\
\hline Minimum & $2.02472 \mathrm{e}-08$ & $\{3.67109,6.58611,-0.170628\}$ \\
\hline Maximum & 0.000233219 & $\{-2.56352,6.66458,3.28\}$ \\
\hline
\end{tabular}

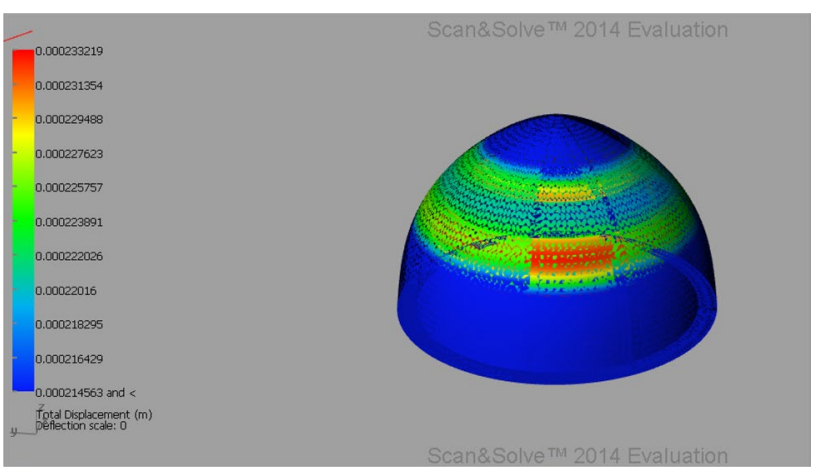

Fig. 6 Total displacement analysis. Source: Authors

\subsection{Structural factor (structure)}

The important factor of aesthetics is related to the role of structure dealing with its relation to form. This factor is realized more when structure has deeper integration to form. The building structure was modeled based on the assumption of cultural heritage. Tension and compression loading simulation was conducted based on the material's properties and their resistance. We developed a model to analyze the structural behavior by application of a numerical tool based on the generalized finite element method. The goal of the method is to construct analysis methods. The adaptive mesh mechanisms are coming in the Scan \& Solve plugin for Rhino software (Table 1).

As illustrated in Fig. 6, the total displacement was less than 0.0002 meters at the maximum mode and the area was considered the most critical point where all loads were simultaneously applied.

The Von-Mises stress is derived from distortion energy failure theory. The failure in structures occur if the VonMises stress exceeds the specified yield stress. As shown in Fig. 7, the maximum Von-Mises stress at the joint bearing surfaces was between $2.3 \times 10^{6}-3.5 \times 10^{6}$, which was less than the yield stress of the materials used.

In addition, as displayed in Fig. 8, the simulation was analyzed based on Mohr-Coulomb theory. The theory was used for static loading and friction angle in brittle materials such as brick-masonry having a compressive

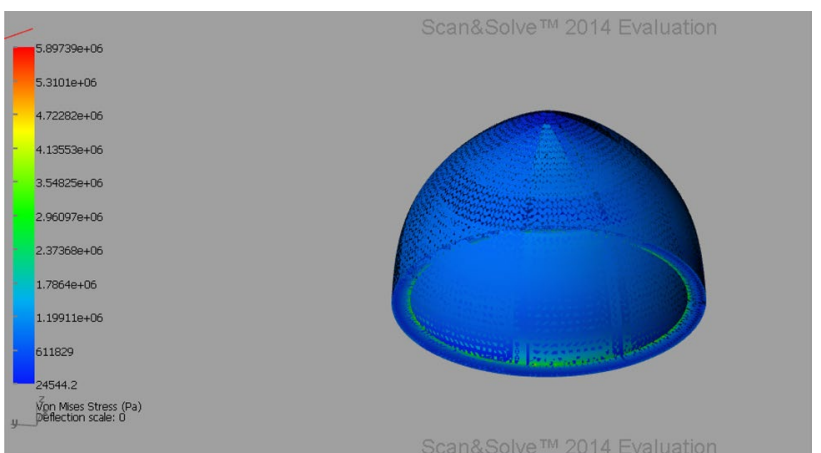

Fig. 7 Finite Element Analysis of Von-Mises stresses. Source: Authors

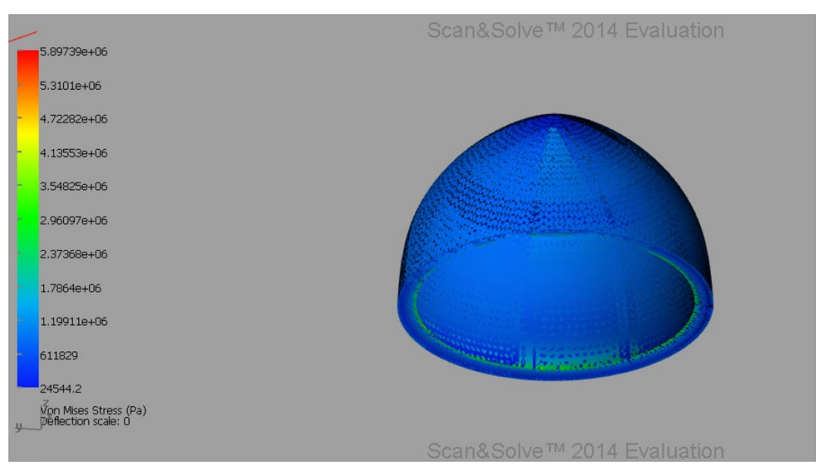

Fig. 8 Risk level analysis. Source: Authors

resistance greater than the tensile resistance. Almost the entire structure is below the standard risk level and the value reaches 1 in insignificant areas as it indicates the strength of the structure against normal and shear stress.

Based on the findings, the dome has the maximum resistance to loading according to the geometry type, materials, ratios, and construction method in such a way that it involves the minimum possible value at risk level analysis which can be disregarded.

\subsection{Structural factor (materials)}

The structure as the building's skeleton made of bricks and mortar. Brick, as the main material of the dome, plays a structural and decorative function not apart from each other but as a whole. A variety of decorating methods were used for creating a pleasant visual space based on mathematical calculations to reduce and divide applied forces to the building. The special decorations used in the dome governing the solid skeleton and organic strength to the entire building (Fig. 9). 


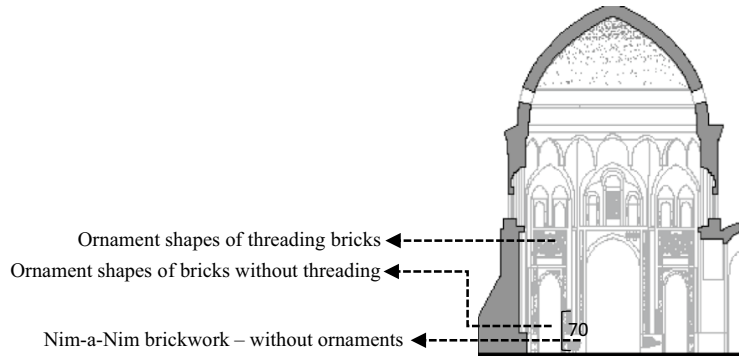

Fig. 9 Analysis of brickwork wall

Fig. 10 Brickwork and ornament on the wall of west vault in the southern entrance (Force distribution analysis)
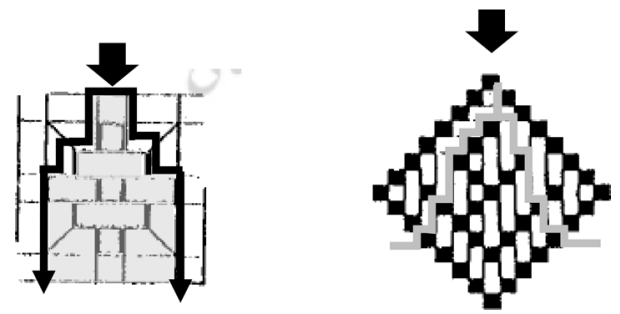

Fig. 11 Khofte-Raste ornaments. The main brickwork features of the building (Force distribution analysis)

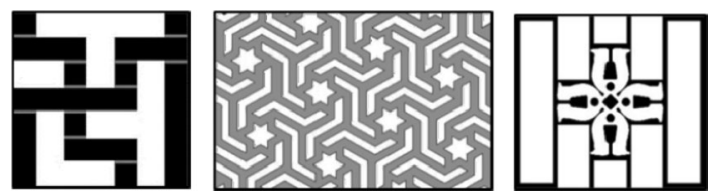

Fig. 12 The details of Dome chamber brick decoration

Different techniques of brick decoration such as straight Khofte-Rasteh ${ }^{2}$ techniques were used at the top of the dome (Figs. 10, 11) [22]. These brick decorations are often ornamented with gypsum threading (Figs. 12, 13).

\footnotetext{
2 Khofte-raste [khəufte $r \wedge$ ste]: Issued for highlighting the designs especially at height such as the decorations of Minarets [22].
}

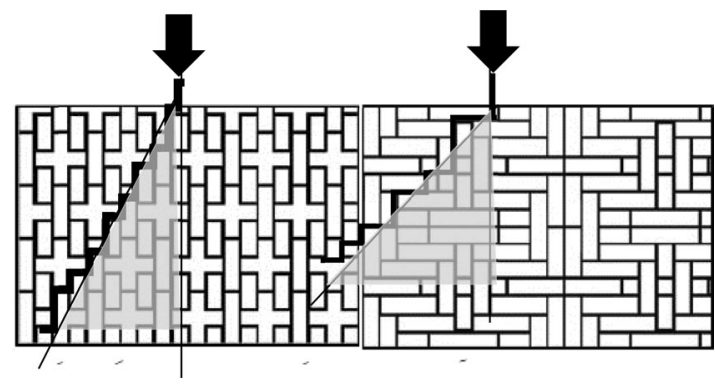

Fig. 13 Force distribution in the brick wall of the dome

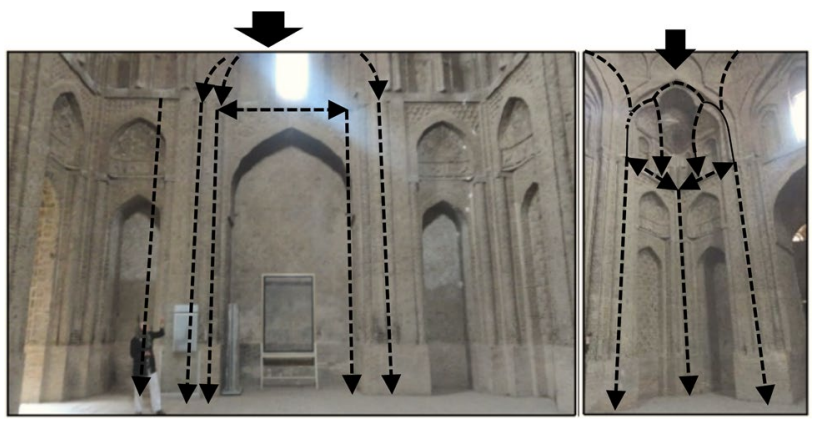

Fig. 14 Internal façade and corner transition of Taj-OI-Molk Dome and force loading schemes

\subsection{Structural factor (connections)}

Precise connection of walls to each other, dome to walls, and brick ridges can be mentioned from the perspective of connection analysis. Brick ridges adapt to the variable forces and neutralize the presence of different forces. The technique includes the Squinch ${ }^{3}$,

Filgoush and Goushvar ${ }^{4}$, dividing and distributing the forces, bearing different loads, and forming a circular shape for the dome on top of the square base. The evolution of corner transition as Patkane ${ }^{5}$ use of continuous double-shell domes with more resistance and less weight

\footnotetext{
3 Squinch: A construction filling in the upper angles of a square room so as to form a base to receive an octagonal or spherical dome [23].

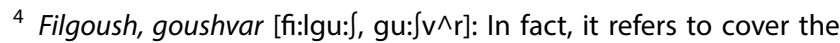
corner wall starting from the corner and located between the two cross-sectional walls.

5 Patkaneh [pǽtk^ne]: A set of niche-like components arranged in successive tiers in a definite geometrical regime [23].
} 
Table 2 The steps of implementing the dome with a quadrangle base in Taj-Ol-Molk Dome

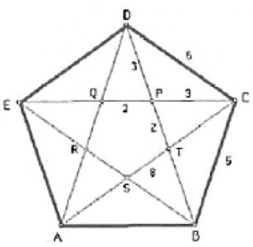

Length(Segment CAYLengthisegment $C \theta)=1.018$

Length(Segment PDyLength(Segment $\mathrm{PD})=1.018$

Length(Segment CByLength $($ Segment $P C)=1.018$

Fig. 15 The Golden ratio in a pentagram

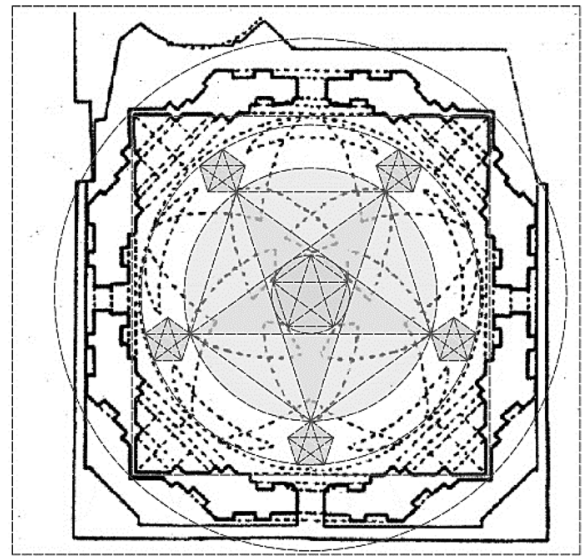

Fig. 16 Analysis of the pentagram and Golden ratio in the reverse plan

can be achieved as a fruit of structural technology in the era (Fig. 14, Table 2).

\section{Form}

Ratio as the main aesthetic criteria was analyzed while studying the form of dome. A pentagon on the flat surface is achieved if a dodecahedron is considered in the geometry of the dome. By connecting the five vertices, the pentagram is created and by connecting the star points, pentagons and other starts are obtained. A pentagram is represents the Golden Ratio (Fig. 15).

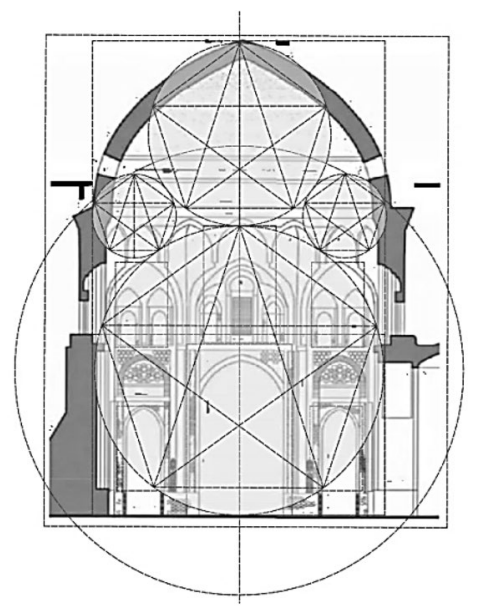

Fig. 17 Analysis of the pentagram and Golden ratio in the cross section of Taj-OI-Molk Dome

The system created a system of proportion used in the dome. The golden ratio in the façade of building coordinated the cross section, the starting point of the arch and dome-span. Focusing on the central pentagon created a significant integrity in the building (Figs. 16, 17).

\section{Nature}

As stated earlier, pure structural messages originate in the fundamental understanding of the structural behavior [7]. Observing the thickness of walls having high piers at the bases and lower piers at the top of the dome and form of the dome are similar to the natural phenomena such as mountains lead to aesthetic perception.

The "catenary curve" is used to eliminate the tensile forces and horizontal thrust of the dome which is the result of natural phenomena [16]. Also, based on the conducted studies, the form of Taj-Ol-Molk Dome is completely in harmony with the catenary curve form. The structural patterns lead to the bearing stress as completely compressive and without tensile and bending stress (Fig. 18). 


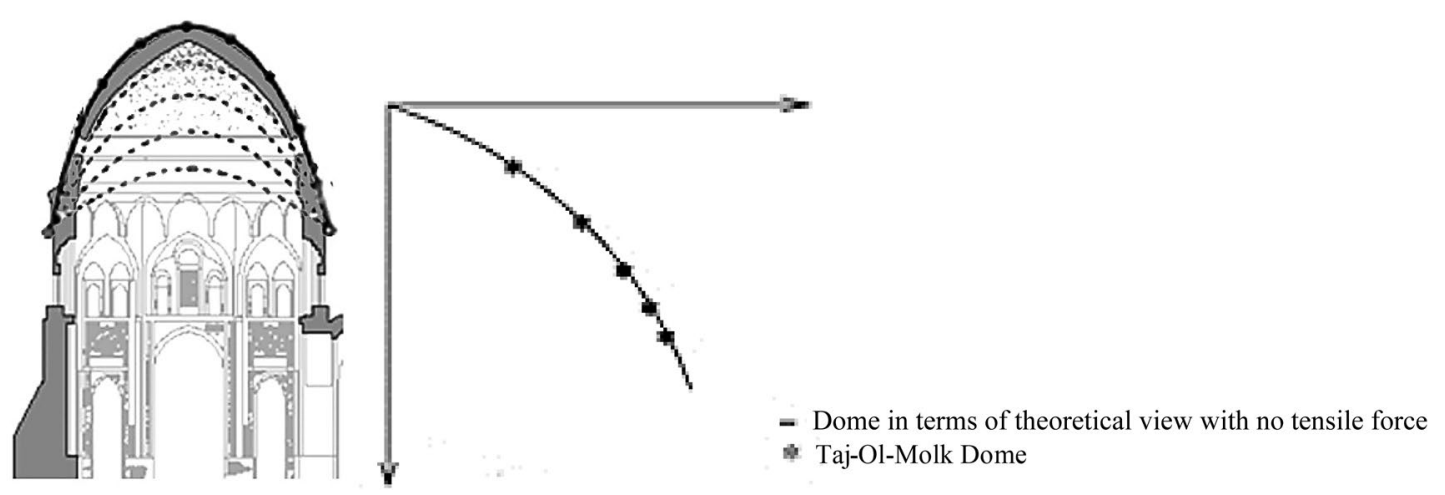

Fig. 18 Comparison of the meridian curve of the dome in terms of theory and empirical research in Taj-Ol-Molk Dome
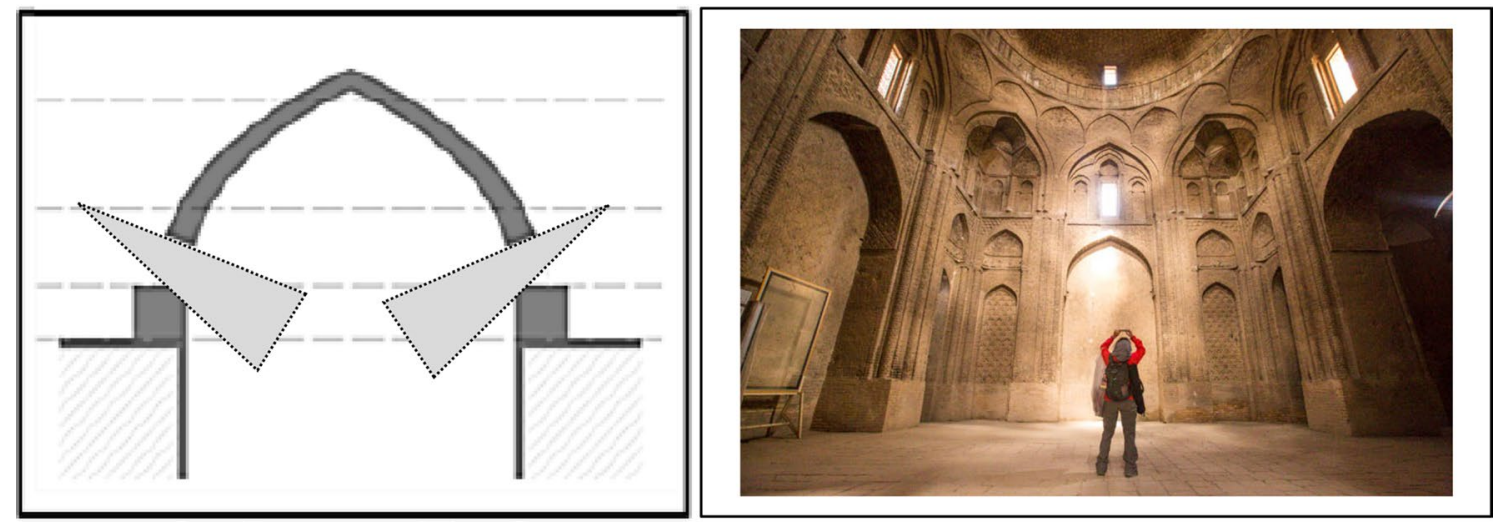

Fig. 19 Analysis of light's criteria in Taj-Ol-Molk Dome

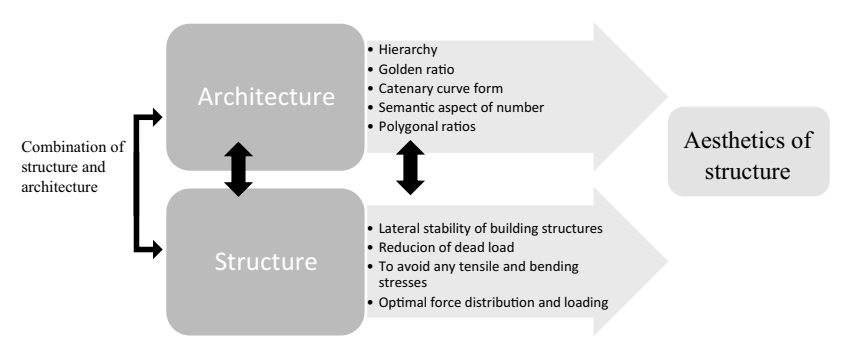

Fig. 20 The combination of architecture and structure

\section{Mystical factor: divine manifestation}

The general geometry at the north dome of Jameh Mosque of Isfahan displays the movement from plurality to unity and from earth to the cosmos. The square chamber plan is transformed into an octagon, hexadecagon and a 32 sided polygon to support the dome.
In Iran, the presence of light has been considered in various architectural spaces from the Pre-Islamic to postIslamic periods, but largely in association with religion and ritual. Sign and symbol such as light is divine manifestation (Figs. 19, 20).

\section{Conclusion}

According to simulation findings, the displacement in the most critical point under all the experimental conditions simultaneously is very negligible and close to zero. Also, the amount of Von-Mises stress at the joint bearing surfaces was between $2.3 \times 10^{6}-3.5 \times 10^{6}$, which was less than the yield stress of the structural materials. According to Mohr-Coulomb theory, almost the entire structure is below the standard risk level and the value reaches 1 in insignificant areas as it shows the strength of the structure against normal and shear stress. Furthermore, some connections include the Squinch, Filgoush and Goushvar distributing the forces, bearing different 
Table 3 The principles of structural aesthetics

\begin{tabular}{|c|c|}
\hline Evaluation criteria & Building realization techniques \\
\hline Structural factor (structure) & $\begin{array}{l}\text { Compressive stress is applied } \\
\text { Applied stresses are less than the allowed stress and being below the standard risk level } \\
\text { Loading is based on meridian curves } \\
\text { Minimum displacement is at the critical point }\end{array}$ \\
\hline Structural factor (materials) & $\begin{array}{l}\text { The use of brick decoration based on mathematical patterns or technical function to reduce and } \\
\text { distribute tensile and compressive forces }\end{array}$ \\
\hline Structural factor (details) & Application of structural details having spiritual characteristics beyond the aesthetic aspects \\
\hline Structural factor (connections) & $\begin{array}{l}\text { The use of architectural form elements such as Squinch, Filgoush and Goushvar responsible for the } \\
\text { distributing the forces, bearing different loads and forming the circular shape for the dome on top } \\
\text { of the square base }\end{array}$ \\
\hline Formal factor (composition) & $\begin{array}{l}\text { Application of Golden ratio rule } \\
\text { Properties of regular pentagon }\end{array}$ \\
\hline Naturalism & $\begin{array}{l}\text { Sensory perception as phenomenon in nature and pure form such as mountains } \\
\text { Matching the shape of the dome with a catenary curve }\end{array}$ \\
\hline Mystical factor & $\begin{array}{l}\text { Dome form is indicative of the plurality in unity } \\
\text { Application of light with semantic and divine significance }\end{array}$ \\
\hline
\end{tabular}

loads, and forming a circular shape for the dome on top of the square base. In terms of structural technologies, we witness fantastic mono-shell dome with more resistance and less weight.

The results of the brickwork analysis indicated that a variety of decorating methods were used for creating a pleasant visual space based on mathematical calculations to reduce applied forces to the building. The special brickworks used in the building governing the solid skeleton and organic strength to the entire dome. The proportion is the most fundamental aspect of aesthetics experience. The form of dome is completely in harmony with the catenary curve form. The structural patterns lead to the bearing stress as completely compressive and without tensile and bending stress. The behavior is completely in accordance with brick's physical characteristics (zero tensile and bending resistance).

The gradual transition of walls into roof implied a kind of movement from plurality to unity. The presence of light has been effective to create a livable space which was a balance of aesthetic and function.

The structural features of Taj-Ol-Molk Dome indicated the aesthetic beauty which can be considered as the most beautiful mono-shell dome. A significant step can be taken towards addressing the continuity of the contemporary and traditional architectures by using the techniques of the criteria.

The study indicated that the principles of structural aesthetics can be considered as a solution to contemporary architecture to create a building with eye-catching facade, stability, lightness, dead load reduction, resistance to lateral loads, and earthquake (Table 3).

\section{Compliance with ethical standards}

Conflict of interest The authors declare that they have no conflict of interest.

\section{References}

1. Macdonald AJ (2007) Structure and architecture. Routledge, London

2. Azhand $Y$ (2014) History of aesthetics and art critics. Mola Publication, Tehran

3. Schlaich M (2015) Elegant structures. In: IABSE Symposium Report, vol 104, no. 41. International Association for Bridge and Structural Engineering, pp 1-7

4. Golabchi M, Soroushnia E (2015) Architecture in detail. University of Tehran Press, Tehran

5. Alemi B, Pourdeihimi S, Mashayekh Faridani S (2016) Structure, form and architecture. J Iran Archit Stud 1(9):123-140

6. Sadeghi S (2016) Designing a cultural center by analyzing the structural aesthetics in architecture. Case study: Mashhad, Master thesis, Iran University of Science and Technology

7. Salvadori M, Heller RA (1975) Structure in architecture: the building of buildings. Prentice-Hall, Englewood Cliffs, NJ

8. Faber O (1941) Aesthetics of engineering structures, vol 5264. ICE Publishing

9. Kollar $L$ (2003) Aesthetic aspects of the design of engineering. J Period Polytech Ser Civ Eng 1:85-94

10. Corbusier L (2013) Towards a new architecture. Courier Corporation, MA

11. Margolius I (2002) Architects + engineers = structures, 1st edn. Academy Press, London

12. Kadoi $Y$ (2016) Arthur upham pope and a new survey of Persian art. Brill, Boston

13. Andrew C (2005) Structure as architecture: a Source Book for architects and structural engineers. Architectural Press, New York

14. Ardalan N, Bakhtiar $L$ (2000) The sense of unity: the Sufi tradition in Persian architecture, 2nd edn. Kazi Publication, Inc, Chicago

15. Kadoi Y (2016) Arthur Upham Pope and a new survey of Persian art. Brill, Boston 
16. Ashkan M, Ahmad Y (2009) Persian domes: history, morphology and typologies. Int J Archit Res: ArchNet-IJAR 3(3):98-115

17. Salehi Kakhki A, Azizpour S, Rahimi Ariaee A (2013) Recognition of architectural features and inscriptions of the Seljuk period in Taj-Ol-Molk Dome. Athar J 64:49-66

18. Hejazi M, Mehdizadeh Saradj F (2014) Persian architectural heritage: architecture, structure and conservation. WIT Press, Southampton

19. Pope A, Ackerman F, Schroeder E (1959) The artworks of Iran, 2 nd edn. Translated by Parviz Khanlari. Tehran Scientific and Cultural Company

20. Pope A, Ackerman F, Besterman T (1964) A survey of Persian art from prehistoric times to the present. Oxford University Press, Oxford
21. Groat LN, Wang D (2013) Architectural research methods. Wiley, New Jersey

22. Hatam GH (2000) Iranian architecture in Seljuk period. Jahad daneshgahi press, Tehran

23. Memarian Gh (2008) Iranian architecture. Soroush Danesh Press, Tehran

Publisher's Note Springer Nature remains neutral with regard to jurisdictional claims in published maps and institutional affiliations. 